\title{
Evaluation of CCR5 $\Delta 32$ Polymorphism in Patients with Systemic Lupus Erythematosus and Healthy Individuals
}

Zahra Heydarifard (MSc) Research Committee Student, School of Medicine, Golestan University of Medical Sciences, Gorgan, Iran Alijan Tabarraei (PhD) Infectious Disease Research Center, Golestan University of Medical Sciences, Gorgan, Iran

Nafiseh Abdollahi (PhD) Bone, Joint and Connective Tissue Research Center, Golestan University of Medical Sciences, Gorgan, Iran Abdolvahab Moradi (PhD) Infectious Disease Research Center, Golestan University of Medical Sciences, Gorgan, Iran

Yosef Khanjari (MSc)

Research Committee Student, School of Medicine, Golestan University of Medical Sciences, Gorgan, Iran

Corresponding author: Alijan Tabarraei

Email: Tabarraei@goums.ac.ir Tel: +989112733321

Address: Golestan University of Medical Sciences, Gorgan, Iran

Received : 02 Jun 2017

Revised: 01 Aug 2017

Accepted: 29 Aug 2017

Zahra Heydarifard https://orcid.org/0000-0002 2093-819X

Alijan Tabarraei http://orcid.org/0000-0002 8167-5469

Nafiseh Abdollahi http://orcid.org/00000003-1190-5449

Abdolvahab Moradi http://orcid.org/00000003-2877-4190
ABSTRACT

Background and Objectives: C-C chemokine receptor type 5 (CCR5) is a chemokine receptor expressed at high levels on the surface of T-cells. A 32-bp deletion in the coding region of the CCR5 (CCR5 $\triangle 32$ ) leads to production of an incomplete protein that is not expressed on the cell surface. CCR5 $\Delta 32$ may be involved in development of autoimmune disease, such as systemic lupus erythematosus. We investigated frequency of the CCR5 $\Delta 32$ polymorphism in SLE patients and healthy controls, and evaluated the relationship between the CCR5 $\triangle 32$ polymorphism and susceptibility to SLE in Golestan Province, Iran.

Methods: Whole blood samples were taken from 00 SLE patients admitted to Shahid Sayyad Shirazi hospital and 80 healthy controls (from a blood bank) in the Golestan Province, in 2016. Baseline clinical and laboratorial characteristics were evaluated regarding the CCR5 $\Delta 32$ genotypes. The CCR5 $\Delta 32$ polymorphism was determined from genomic DNA by polymerase chain reaction.

Result: Genotype frequencies of both groups were in the Hardy-Weinberg equilibrium. The frequencies of the CCR5 and the CCR5 $\triangle 32$ alleles were $98.13 \%$ and $1.80 \%$ among the patients, and $98.75 \%$ and $1.25 \%$ among the controls, respectively. Homozygote CCR5 $\Delta 32$ was not observed in the subjects. The frequency of heterozygous $\Delta 32$ was $3.0 \%$ and $2.5 \%$ among the SLE patients and controls, respectively (P-value $>0.05$ ). There was no significant association between the CCR5 status and clinical signs of SLE ( $P>0.05)$.

Conclusion: 0ur data suggest that the CCR5 $\triangle 32$ polymorphism has no correlation with SLE in our study population. In addition, the frequency of the $\Delta 32$ polymorphism in SLE patients and controls does not follow the Hardy-Weinberg equilibrium

Keywords: CCR5, Homozygote CCR5 $\Delta 32$, Heterozygote CCR5 $\triangle 32$, CCR5 332 allele, SLE.

This paper should be cited as: Heydarifard z, Tabarraei $A$, Abdollahi N, Moradi A, Khanjari Y [Evaluation of CCR5 $\triangle 32$ Polymorphism in Patients with Systemic Lupus Erythematosus and Healthy Individuals]. mljgoums. 2018; 12(2): 38-43. DOI: 10.29252/mlj.12.2.38 


\section{INTRODUCTION}

Chemokines are a family of proteins that have an important role in inflammation and the accumulation of inflammatory cells such as leukocytes, lymphocytes, and macrophages via interaction with chemokine receptors on the surface of these cells (1). They are also of great importance in homeostatic and inflammatory conditions. Increased levels of chemokines and chemokine receptors have been found in several autoimmune diseases (2). C-C chemokine receptor type 5 (CCR5) has several ligands, including RANTES, MIP $\beta$, MIP $\alpha$, and MCP-2. It is expressed at high levels on the surface of T-cells and plays a major role in the T-cell recruitment. A 32-bp deletion in the coding region of the CCR5 (CCR5 432$)$ induces an early frame shift of stop codon within the third extracellular domain and leads to production of an incomplete protein incapable of expressing on the cell surface $(3,4)$. Distribution of the CCR5 $\Delta 32$ varies in different populations (5).

Frequency of the CCR $5 \Delta 32$ allele also varies in different ethnic groups, with the highest frequency $(10-15 \%)$ in Caucasians, and the lowest (2\%) in African-Americans (6). The clinical importance of $\Delta 32$ deletion was identified for the first time in HIV infection. While CCR5 acts as a co-receptor for HIV, homozygous $\Delta 32$ deletion results in almost complete resistance to HIV (7). Subsequently, the $\Delta 32$ deletion has also been reported to have a protective effect on the development and progression of several autoimmune diseases, including rheumatoid arthritis (RA), inflammatory kidney disease, and rejection of solid organ allografts (8). Systemic lupus erythematosus (SLE) or lupus is an autoimmune disease that affects several body organs and cells. The immune complex deposition containing nuclear antigens and antibodies causes a variety clinical symptoms such as skin rashes, arthritis, and glomerulonephritis $(9,10)$. In terms of diagnosis, detection of autoantibodies, particularly anti-nuclear antibodies (ANAs) is important, because the test is positive in 95\% of patients (usually upon manifestation of symptoms)(11). Lupus affects women more than men and its symptoms usually appear in the third and fourth decades of life (12). Role of the CCR $5 \Delta 32$ in the pathogenesis of lupus varies among different populations (13). Although some studies on patients with this mutation have shown the protective effects on the development and prognosis of lupus, such effects has not been confirmed in other studies (14). Given the importance of genetic predisposition in the development and prognosis of lupus, we examined the frequency of CCR5 $\triangle 32$ mutation in SLE patients and healthy individuals from the Golestan Province, Iran.

\section{MATERIAL AND METHODS}

Whole blood samples were taken from 80 SLE patients admitted to Shahid Sayyad Shirazi hospital and 80 healthy controls (from a blood bank) in the Golestan Province, in 2016. The samples were matched with age, gender, and ethnicity. Clinical and demographic data were collected through standard questionnaires and medical records. Ethnic groups were classified in four categories of Fars, Turkmen, Sistani, and Baloch. Serum C3 and C4 levels (mg/dl) were measured by nephelometry. Antibodies against double-stranded DNA (anti-dsDNA) were quantified using enzyme-linked immunoassay (ELISA, anti-dsDNA, Orgentec Diagnostika, $\mathrm{GmbH}$, Germany). Titers $\geq 20 \mathrm{IU} / \mathrm{mL}$ were considered significant. Peripheral white blood cells were quantified using an automatic method and expressed as cells $/ \mathrm{mm}^{3}$. Clinical manifestations and therapeutic data were obtained from medical records.

Genomic DNA was extracted from peripheral blood cells using Kiagen DNA extraction kits (Kiagen Co., Iran). The CCR5 gene was amplified using polymerase chain reaction (PCR), and a 276-bp fragment was obtained using the following primers: sense 5'CGTCTCTCCCAGGAATCATC-3' and antisense 5'AGGGAGCCCAGAAGAGAAAA-3' (15). PCR was also used for CCR5 $\triangle 32$ genotyping. The PCR reaction solution $(25 \mu \mathrm{l})$ contained 50-100 ng of genomic DNA, 10 pmol of each primer, $0.3 \mathrm{mM}$ dNTPs, $1.5 \mathrm{mM} \mathrm{MgCl}_{2}, 1 \mathrm{x}$ PCR buffer (10 mM Tris-HCL PH:8.3, $50 \mathrm{mM}$ $\mathrm{KCL}, 1.5 \mathrm{MgCl}_{2}$ and $0.001 \%$ (w/v) gelatin), and 1.5 unit of Taq DNA polymerase. Thermal amplification was done by starting with initial denaturation at $95{ }^{\circ} \mathrm{C}$ for $5 \mathrm{~min}$. It was followed by 35 cycles of denaturation at $95{ }^{\circ} \mathrm{C}$ for $1 \mathrm{~min}$, annealing at $62{ }^{\circ} \mathrm{C}$ for 1 min, extension at $72{ }^{\circ} \mathrm{C}$, and final extension at $72^{\circ} \mathrm{C}$. The wild-type and variant alleles 
produced $276 \mathrm{bp}$ and $244 \mathrm{bp}$ fragments, respectively.Negative control (without DNA sample) was included in each set of PCR. Electrophoresis was done on 3\% agarose gel and bands were detected with SYBR Green I stain.

Distribution of the CCR5 alleles was evaluated using the Hardy-Weinberg (HWN) $\underline{(a+2 a)}$

equation: $\frac{2 N}{2 N}$, in which $\mathrm{A}$ is the number of wild type genotype, $a$ is the number of heterozygote genotype, $\mathrm{N}$ is the number of total samples, and df (degree of freedom) is the subtraction of total genotypes and alleles numbers. Statistical analysis was performed using SPSS 16.0. The frequency was further analyzed using the Hardy-Weinberg equilibrium. Differences in the frequency of each genetic variant between the healthy and SLE groups were assessed by Chi-square test or the fisher exact test, followed by calculation of odds ratio at $95 \%$ confidence interval (CI). P-values less than 0.05 were considered statistically significant.

\section{RESULTS}

Demographic, clinical, and experimental characteristics of the SLE patients are shownin Error! Reference source not found. and Table 2. The patients were mainly of Fars $(65 \%)$ ethnicity with mean age of $38.66 \pm 13$ years.

The distribution of the CCR5 $\Delta 32$ genotypes and alleles was in the Hardy-Weinberg equilibrium for both subgroups. There was no statistically significant difference in the genotype frequency between the SLE patients and healthy controls (Table 23).

The homozygosity for the CCR5 wild-type allele, the heterozygosity for the CCR $5 \Delta 32$ variant allele, and the homozygosity for the variant allele were seen in $77(96.2 \%), 3$ $(3.8 \%)$, and none of the patients, respectively.

Moreover, the homozygosity for the CCR5 wild-type allele, the heterozygosity for the CCR5 $\triangle 32$ variant allele, and the homozygosity for the variant allele were seen in $78(97.5 \%), 2(2.5 \%)$, and none of the controls, respectively.

Frequencies of the CCR 5 and the CCR $5 \Delta 32$ alleles were $98.13 \%$ and $1.88 \%$ among the SLE patients, and $98.75 \%$ and $1.25 \%$ among the controls, respectively.

Table 1- Clinical characteristics of patients with SLE and healthy controls

\begin{tabular}{lll}
\hline Characteristics & $\begin{array}{l}\text { SLE patients } \\
(\mathrm{N}=80)\end{array}$ & $\begin{array}{l}\text { Healthy controls } \\
(\mathrm{N}=80)\end{array}$ \\
\hline Age(mean \pm SD) & $\mathbf{3 8 . 6 6} \pm 13.49$ & $44.52 \pm 22.39$ \\
Number of females(\%) & $41(51.2 \%)$ & $\mathbf{7 4}(92.5 \%)$ \\
Ethnicity & Number $(\%)$ & \\
Fars & $52(65 \%)$ & $\mathbf{4 0}(50 \%)$ \\
Turkaman & $16(20 \%)$ & $\mathbf{2 5}(13.2 \%)$ \\
Sistani & $10(12.5 \%)$ & $15(18.8 \%)$ \\
Baloch & $2(2.5 \%)$ & - \\
\hline
\end{tabular}

Table 2- Frequency of the CCR5 $\triangle 32$ polymorphism in SLE patients and healthy controls from the Golestan Province. Iran

\begin{tabular}{|c|c|c|}
\hline Characteristics & $\begin{array}{c}\text { SLE patients } \\
(\mathbf{N}=\mathbf{8 0})\end{array}$ & $\begin{array}{c}\text { Healthy controls } \\
(\mathrm{N}=\mathbf{8 0})\end{array}$ \\
\hline $\begin{array}{l}\text { Anti-dsDNA (IU/mL) } \\
\text { Negative }(<20 \text { IU/mL) }\end{array}$ & $21(30.4 \%)$ & - \\
\hline Positive ( $\geq 20 \mathrm{IU} / \mathrm{mL})$ & $48(69.6 \%)$ & \\
\hline WBC count $($ Mean \pm SD) & $2187.62 \pm 437.02$ & - \\
\hline $\operatorname{ESR}(\operatorname{Mean} \pm \mathrm{SD})$ & $32.05 \pm 3.66$ & - \\
\hline C3 $($ Mean \pm SD) & $1.38 \pm 0.06$ & - \\
\hline C4 (Mean \pm SD) & $0.25 \pm 0.02$ & - \\
\hline ANCA $($ Mean \pm SD) & $4.10 \pm 1.58$ & - \\
\hline Positive CRP, n (\%) & $13(17.1 \%)$ & - \\
\hline ANA (Mean \pm SD) & $4.66 \pm 1.90$ & - \\
\hline Renal involvement, n (\%) & $21(27.6 \%)$ & - \\
\hline
\end{tabular}


Based on ethnicity, the highest frequency of heterozygous CCR5 $\Delta 32$ and $\Delta 32$ allele in SLE patients was observed among Turkmen $(6.2 \%$ and $3.1 \%)$ and Fars (3.8\% and $1.9 \%)$, respectively. The mutation was not found in Sistani patients. The frequency of heterozygous $\Delta 32$ among SLE patients and controls was $3.8 \%$ and $2.5 \%$, respectively. No statistically significant difference was detected between the two groups in terms of gender, ANA, C3, C4, and anti-dsDNA ( $>>0.05)$. Independent of the CCR $5 \Delta 32$ polymorphism, there was no statistically significant difference in the rate of anti-dsDNA positivity among Turkmen (78.6\%), Sistani (75.6\%), Fars $(65.2 \%)$ and Baloch $(50 \%)$ subjects $(\mathrm{P}>0.05)$.

Data are expressed in absolute number $(n)$ and percentages. The distribution of genotypes and allelic frequencies was in the Hardy-Weinberg equilibrium (Chi-square test, $\mathrm{P}>0.05$ ).

\section{DISCUSSION}

We found no significant association between the CCR5 $\Delta 32$ mutations (heterozygous and homozygous alleles) and SLE patients in the Golestan Province. However, the frequency of this polymorphism in Turkmen patients was higher than that in other ethnic groups, but this difference was not statistically significant. Frequency of the $\Delta 32$ mutation in our study was similar to previous studies in Iran $(5,16,17)$. Our results are also similar to findings of Aguilar et al. in Spain, which reported no significant association between the $\Delta 32$ polymorphism and development of SLE (18). In study of Martens et al. in the Netherlands, frequency of the $\Delta 32$ allele was $1.2 \%$ in SLE patients and $8.2 \%$ in healthy controls, indicating the lack of a significant relationship between the mutations and disease severity (8). However, Baltus et al. (14) and Mamtani et al. reported significant associations between the polymorphism and severity of SLE (19). A previous study stated that there might be a significant association between the CCR5 $\triangle 32$ genotype and age at onset of SLE. In addition, the polymorphism could be associated with a reduced risk and delayed age of onset, and severity of SLE (14). We found a significant association between SLE patients with the $\Delta 32$ mutation and clinical signs. In a study by Baltus, the patients carrying the CCR5 32 allele showed higher level of anti-dsDNA compared to the patients with the wild-type genotype, but this difference was not statistically significant (14). In our study, the frequency of the CCR $5 \Delta 32$ heterozygous genotype was $3.8 \%$ and $2.5 \%$ in SLE patients and controls, respectively. Study of Carvalho et al. in Portugal concluded that the $\Delta 32$ polymorphism could have a protective effect against development of SLE due to low frequency of the $\Delta 32$ heterozygote genotype in the SLE patients compared to the controls (20). Frequency of the CCR $5 \Delta 32$ polymorphism is reported to be $5-16 \%$ in European countries, but almost nonexistent in African, Japanese, and Chinese people (21). Previous studies have also reported the low frequency of this allele in Iran (22). The CCR5 expressed on the surface of immune cells is involved in overexpression of proinflammatory cytokines (23). In SLE, inflammatory processes starts with lymphocytic infiltration into tissue space, and biodistribution of lymphocytes at the inflammation site can be determined by expression of some chemokine receptors such as CCR5 (24). The CCR5 $\Delta 32$ reduces expression of the protein and disrupts its function, effects that are crucial in development of autoimmune diseases (25). CCR5 is a chemokine receptor involved in inflammatory responses and could, therefore, trigger autoimmune disease. On the other hand, abundance of these receptors on the surface of Treg cells could increase production of IL-10, which is an anti-inflammatory cytokine. Thus, the role of CCR5 in induction or prevention of SLE is not clear. (14). Some studies have suggested an association between the CCR5 $\triangle 32$ polymorphism and the severity of SLE. It is known that the TregCCR5 ${ }^{+/+}$cells express higher levels of the anti-inflammatory cytokine IL-10 compared to TregCCR5 ${ }^{-/}$(26). The protective effect of this mutation on SLE patients has been attributed to increased expression of CCR5 in Th1 cells in active SLE patients compared to SLE patients with clinical remission and healthy individuals (27, 28).

\section{CONCLUSION}

Our data suggest that the CCR5 $\triangle 32$ polymorphism has no correlation with SLE patients in the Golestan Province.

In addition, the frequency of $\Delta 32$ polymorphism in SLE patients and controls does not follow the Hardy-Weinberg equilibrium. 


\section{ACKNOWLEDGMENTS}

This article has been derived from a project supported by a grant (35/274052) from the Infectious Diseases Research Center of the

\section{REFERENCES}

1. Blanpain C, Doranz BJ, Bondue A, Govaerts C, De Leener A, Vassart $\mathrm{G}$, et al. The core domain of chemokines binds CCR5 extracellular domains while their amino terminus interacts with the transmembrane helix bundle. Journal of Biological Chemistry. 2003; 278(7): 5179-87.

2. Gade-Andavolu R, Comings DE, MacMurray J, Rostamkhani M, Cheng LS-C, Tourtellotte WW, et al. Association of CCR5 432 deletion with early death in multiple sclerosis. Genetics in Medicine. 2004; 6(3): 126-31. DOI:10.109701.GIM.0000127274.45301.54.

3. Salem AH, Farid E, Fadel R, Abu-Hijleh M, Almawi $\mathrm{W}$, Han K, et al. Distribution of four HIV type 1resistance polymorphisms (CCR5- $\triangle$ 32, CCR5-m303, CCR2-64I, and SDF1-3'A) in the Bahraini population. AIDS research and human retroviruses. 2009; 25(10): 973-7. doi: 10.1089/aid.2009.0066.

4. Grimaldi R, Shindo N, Acosta A, Dourado I, Brites C, de Melo Carvalho O, et al. Prevalence of the CCR5 32 mutation in Brazilian populations and cell susceptibility to HIV-1 infection. Human genetics. 2002; 111(1): 102-4.

5. Gharagozloo M, Doroudchi M, Farjadian S, Pezeshki $\mathrm{AM}$, Ghaderi A. The frequency of CCR5 32 and CCR2$64 I$ in southern Iranian normal population. Immunology letters. 2005; 96(2): 277-81.

6. Adler G, Valjevac A, Skonieczna-Żydecka K, MackicDjurovic M, Parczewski M, Urbańska A, et al. Frequency of CCR5432 allele in healthy Bosniak population. Bosnian Journal of Basic Medical Sciences. 2014; 14(3): 150-4.

7. Lopalco L. CCR5: from natural resistance to a new anti-HIV strategy. Viruses. 2010; 2(2): 574-600.

8. Martens HA, Gross S, van der STEEGE G, Brouwer E, Berden JH, de SEVAUX R, et al. Lack of association of $C C$ chemokine receptor $5 \Delta 32$ deletion status with rheumatoid arthritis, systemic lupus erythematosus, lupus nephritis, and disease severity. The Journal of rheumatology. 2010; 37(11): 2226-31.

9. Longo D, Fauci A, Kasper D, Hauser S, Jameson J, Loscalzo J. Harrison's Principles of Internal Medicine. $18^{\text {th }}$ ed. McGraw-Hill Education; 2011.

10. Zhang J, Dou Y, Zhong Z, Su J, Xu D, Tang F, et al. Clinical characteristics and therapy exploration of active human cytomegalovirus infection in 105 lupus patients. Lupus. 2014;23(9):889-97. doi: $10.1177 / 0961203314532560$.

11. Skare TL, Dagostini JS, Zanardi PI, Nisihara RM. Infections and systemic lupus erythematosus. Einstein (São Paulo). 2016; 14(1): 47-51. doi: 10.1007/s10096014-2098-7.

12. Chen J, Zhang H, Chen P, Lin Q, Zhu X, Zhang L, et al. Correlation between systemic lupus erythematosus and cytomegalovirus infection detected by different methods. Clinical rheumatology. 2015; 34(4): 691-8. doi: 10.1007/s10067-015-2868-3.
Golestan University of Medical Sciences, Iran.

\section{CONFLICT OF INTEREST}

The authors declare that they have no conflict of interest.

13. Zakeri Z, Shakiba M, Narouie B, Mladkova N, Ghasemi-Rad M, Khosravi A. Prevalence of depression and depressive symptoms in patients with systemic lupus erythematosus: Iranian experience. Rheumatology international. 2012; 32(5):1179-87. doi: 10.1007/s00296010-1791-9.

14. Baltus THL, Kallaur AP, Lozovoy MAB, Morimoto HK, Delongui F, Alfieri DF, et al. CCR5432 (rs333) polymorphism is associated with the susceptibility to systemic lupus erythematosus in female Brazilian patients. Rheumatology international. 2016; 36(1): 7-15. doi: 10.1007/s00296-015-3308-z.

15. Tan X-h, Zhang J-y, Di C-h, Hu A-r, Yang L, Qu S, et al. Distribution of CCR5-432, CCR5m303A, CCR264I and SDF1-3' $A$ in HIV-1 infected and uninfected high-risk Uighurs in Xinjiang, China. Infection, Genetics and Evolution. 2010; 10(2): 268-72. doi: 10.1016/j.meegid.2009.11.015.

16. Arababadi MK, Pourfathollah AA, Jafarzadeh A, Hassanshahi G, Mohit M, Hajghani M, et al. Peripheral blood CD8+ $T$ cells CCR5 expression and its 432 mutation in Iranian patients with occult hepatitis $B$ infections. Lab Medicine. 2010; 41(4): 226-30.

17. Omrani D, Bagheri M. Frequency of CCR5? 32 Variant in North-West of Iran. Journal of Sciences, Islamic Republic of Iran. 2009; 20(2): 105-110.

18. Aguilar F, Núñez-Roldán A, Torres B, Wichmann I, Sánchez-Román J, González-Escribano MF. Chemokine receptor CCR2/CCR5 polymorphism in Spanish patients with systemic lupus erythematosus. The Journal of rheumatology. 2003; 30(8): 1770-4.

19. Mamtani M, Rovin B, Brey R, Camargo JF, Kulkarni $\mathrm{H}$, Herrera $\mathrm{M}$, et al. CCL3L1 gene-containing segmental duplications and polymorphisms in CCR5 affect risk of systemic lupus erythematosus. Annals of the rheumatic diseases. 2008; 67(8): 1076-83. doi: 10.1136/ard.2007.078048.

20. Carvalho C, Calvisi S, Leal B, Bettencourt A, Marinho A, Almeida I, et al. CCR5-Delta32: implications in SLE development. International journal of immunogenetics. 2014; 41(3): 236-41. doi: 10.1111/iji.12094.

21. Silva-Carvalho WHV, de Moura RR, Coelho AVC, Crovella S, Guimarães RL. Frequency of the CCR5delta32 allele in Brazilian populations: A systematic literature review and meta-analysis. Infection, Genetics and Evolution. 2016; 43: 101-7. doi: 10.1016/j.meegid.2016.05.024.

22. Rahimi H, Farajollahi MM, Hosseini A. Distribution of the mutated delta 32 allele of CCR5 co-receptor gene in Iranian population. Medical journal of the Islamic Republic of Iran. 2014; 28:140.

23. Ghorban K, Dadmanesh M, Hassanshahi G, Momeni $\mathrm{M}$, Zare-Bidaki M, Arababadi MK, et al. Is the CCR5 $\triangle$ 32 mutation associated with immune system-related diseases? Inflammation. 2013; 36(3): 633-42. 
24. Hoffman RW. T cells in the pathogenesis of systemic lupus erythematosus. Clinical Immunology. 2004; 113(1): 4-13.

25. Arababadi MK, Naghavi N, Hassanshahi G, Mahmoodi M. Is CCR5-432 mutation associated with diabetic nephropathy in type 2 diabetes? Annals of Saudi medicine. 2009; 29(5): 413. doi: 10.4103/02564947.55177.

26. Dobaczewski M, Xia Y, Bujak M, Gonzalez-Quesada C, Frangogiannis NG. CCR5 signaling suppresses inflammation and reduces adverse remodeling of the infarcted heart, mediating recruitment of regulatory $T$ cells. The American journal of pathology. 2010; 176(5): 2177-87. doi: 10.2353/ajpath.2010.090759.

27. Li Y-m, Chen Z-q, Yao X, Yang A-z, Li A-s, Liu D$\mathrm{m}$, et al. mRNA expression of chemokine receptors on peripheral blood mononuclear cells and correlation with clinical features in systemic lupus erythematosus patients. Chinese Medical Sciences Journal. 2010; 25(3): $162-8$.

28. Al-Saleh J, el-Eissawy S. The role of T helper cell subsets in pathogenesis of Systemic Lupus Erythematosus and their relation to disease activity. The Egyptian journal of immunology/Egyptian Association of Immunologists. 2005; 13(2): 41-8. 